\title{
INFLUÊNCIA DA Commelina diffusa L. NO DESENVOLVIMENTO DE DIFERENTES CULTIVARES DO FEIJOEIRO
}

\author{
Edilson Marques Junior ${ }^{1}$ \\ Patrícia Elisa da Silva Moreira ${ }^{2}$ \\ Marcelo Soares Altoé ${ }^{3}$ \\ Isadora Rodrigues Garcia ${ }^{4}$ \\ Angelo Oliveira Gonçalves ${ }^{5}$ \\ Matheus Ricardo da Rocha ${ }^{6}$ \\ Leandro Pin Dalvi ${ }^{7}$
}

Resumo: A cultura do feijoeiro possui um lugar de destaque na agricultura brasileira, sendo um dos alimentos mais produzidos e consumidos no país. Seu desenvolvimento pode sofrer importantes interferências devido a diversos fatores, dentre eles, a presença de plantas daninhas, que competem por água, luz e nutrientes, causando consideráveis quedas na produtividade da cultura. Objetivou-se com este trabalho avaliar a influência da trapoeraba no desenvolvimento de diferentes cultivares do feijoeiro. $O$ experimento foi conduzido em casa de vegetação, onde quatro cultivares de feijoeiro, sendo elas BRS Estilo, Mulato + Precoce, Carioca Comum e Rosinha Carioca, foram semeadas em vasos, com e sem propágulos de trapoeraba. Posteriormente foram avaliadas diferentes variáveis das plantas adultas: altura da planta, diâmetro do caule, comprimento, largura da folha, número de folhas, número de vagens maduras, número de vagens chochas e número total de vagens. Das cultivares estudadas, apenas o Mulato + Precoce e Carioca Comum foram influenciadas pela trapoeraba, apresentando uma redução significativa na altura das plantas.

Palavras-chave: Feijão; Competição; Trapoeraba; Planta daninha.

\footnotetext{
${ }^{1}$ Universidade Federal do Espírito Santo-CCAE, Brasil. E-mail: edilsonmarquesjr@hotmail.com.

2 Universidade Federal do Espírito Santo-CCAE, Brasil. E-mail: p.eliza@hotmail.com.

3 Universidade Federal do Espírito Santo-CCAE, Brasil. E-mail: marcelosoaresaltoe@hotmail.com.

${ }^{4}$ Universidade Federal do Espírito Santo-CCAE, Brasil. E-mail: isadorargz@hotmail.com.

5 Universidade Federal do Espírito Santo-CCAE, Brasil. E-mail: goncalves.aog@gmail.com.

${ }^{6}$ Universidade Federal do Espírito Santo-CCAE, Brasil. E-mail: matheus.ricardo@hotmail.com.

${ }^{7}$ Universidade Federal do Espírito Santo-CCAE, Brasil. E-mail: leandropin@yahoo.com.br.
} 